\title{
Pre-operative pulmonary assessment for patients with hip fracture
}

\author{
I.-L. Lo $•$ C.-W. Siu $・$ H.-F. Tse $\cdot$ T.-W. Lau $\cdot$ F. Leung $•$ \\ M. Wong
}

Received: 18 August 2010 / Accepted: 4 September 2010

(C) The Author(s) 2010. This article is published with open access at Springerlink.com

\begin{abstract}
Hip fracture is a common injury among the elderly. Although patients who receive hip fracture surgery carry the best functional recovery compared to other treatment modalities, the presence of postoperative pulmonary complications, such as atelectasis, pneumonia, and pulmonary thromboembolism, may contribute to increased length of hospital stay, perioperative morbidity, and mortality. This review aims to provide evidence-based recommendations for preoperative assessment and perioperative strategies to reduce the risk of pulmonary complications after hip fracture surgery. Clinical assessment
\end{abstract}

I.-L. Lo

Department of Respiratory Medicine, Centro Hospital Conde de Sao Januario,

Macau, China

C.-W. Siu $\cdot$ H.-F. Tse

Cardiology Division, Department of Medicine,

Queen Mary Hospital, The University of Hong Kong,

Pokfulam, Hong Kong, China

C.-W. Siu $\cdot$ H.-F. Tse

Research Center of Heart, Brain, Hormone and Healthy Aging,

The University of Hong Kong,

Pokfulam, Hong Kong, China

T.-W. Lau $\cdot$ F. Leung

Department of Orthopaedics \& Traumatology,

The University of Hong Kong,

Pokfulam, Hong Kong, China

M. Wong $(\bowtie)$

Division of Respiratory Medicine, Department of Medicine,

The University of Hong Kong, Queen Mary Hospital,

Pokfulam, Hong Kong, China

e-mail: drmwong@gmail.com and basic laboratory results are sufficient to stratify the risk of postoperative pulmonary complications. Welldocumented risk factors for pulmonary complications include advanced age, poor general health status, current infections, pre-existing cardiopulmonary diseases, hypoalbuminemia, and impaired renal function. Apart from optimizing the patient's medical conditions, interventions such as lung expansion maneuvers and thromboprophylaxis have been proven to be effective in reducing the risk of pulmonary complications after hip fracture surgery.

\section{Keyword Osteoporosis}

\section{Introduction}

Hip fracture is one of the most common injuries among the elderly with high morbidity and mortality [1]. It is estimated that the lifetime risk of a hip fracture is $15 \%$ among 50-year-old white women [2]. The number of hip fractures is likely to rise in the coming decades with the increasing life expectancy and prevalence of osteoporosis [3]. The 1-year mortality after hip fracture is between $20 \%$ and $35 \%$ in the elderly $[4,5]$. Among those who survived at 1 year, only half of them were able to perform activities of daily living [6]. Hip fracture surgery, including hip pinning and hemiarthroplasty, is the mainstay treatment. It has been shown that early hip fracture surgery (within the first 24$48 \mathrm{~h}$ ) is associated with better outcomes in terms of length of stay, functional recovery, and mortality [7-9]. However, failure to stabilize the medical conditions prior to surgery increases the risk of postoperative cardiac and pulmonary complications, hospital readmission, and deaths [10-12]. 
Physicians should therefore strike a balance between early surgery and adequate perioperative assessment and interventions in order to achieve better outcomes and reduce the complications.

Postoperative pulmonary complications (PPCs) are defined as pulmonary abnormalities that result in identifiable disease or dysfunction and adversely impact the patient's clinical course. PPCs are common and contribute to increased length of stay, perioperative morbidity, and mortality $[13,14]$. It has been reported that pulmonary complications affected $4 \%$ of patients after hip fracture repair, and more than half of them were severe complications, such as pneumonia or respiratory failure [15]. A growing body of evidence indicates that PPCs may even predict long-term survival, especially among patients aged 70 or above [16, 17]. Clinical significant PPCs after hip fracture surgery include atelectasis, pneumonia, pulmonary thromboembolism, exacerbation of chronic lung disease, respiratory failure, and acute respiratory distress syndrome (Table 1) [18].

The main purposes of the preoperative pulmonary assessment are: (1) to perform risk stratification according to the analysis of clinical and laboratory risk factors, (2) to determine the potential need for postoperative intensive care, and (3) to implement interventions to reduce the risk of PPCs [19]. While anesthetists take the leading role in pulmonary risk assessment as part of their comprehensive preoperative evaluation, respiratory physicians' input should be sought to identify and manage underlying respiratory diseases before hip fracture surgery in particular, when there is worsening of chronic symptoms or presence of unexplained features.

This review aims to provide evidence-based recommendations for the preoperative pulmonary assessments and perioperative interventions for patients undergoing hip fracture surgery. Other aspects of a comprehensive preoperative assessment, such as cardiac, metabolic, and general assessment, are beyond the scope of this review.

Table 1 Postoperative pulmonary complications after hip fracture surgery

Atelectasis

Pneumonia

Pulmonary thromboembolism

Exacerbation of chronic lung disease

Respiratory failure and prolonged mechanical ventilation

Obstructive sleep apnea

Acute respiratory distress syndrome

Modified from [18]

\section{Risk factors for PPCs}

Different studies may reveal diverse risk factors for PPCs, owing to the variation in methodology such as patient selection, sample size, and definitions of outcomes and predictors [20]. It is also difficult to demonstrate the independent effects of individual predictors since most of the elderly patients have more than one risk factor. Highquality systematic reviews and risk prediction equations have been published to address these problems [21]. For example, Arozullah and colleagues developed a validated pulmonary risk index predictive of pneumonia and respiratory failure after non-cardiothoracic surgery [22-24]. All risk factors for PPCs can be classified into patient-related risk factors and procedure-related risk factors (Table 2) [25].

According to the risk stratification, hip fracture surgery per se is not a high-risk operation for the development of PPCs. However, hip fracture patients are usually elderly with multiple co-morbidities, which make them prone to develop PPCs. Therefore, this review focuses on the patient-related risk factors, especially for patients with hip fracture.

\section{Advanced age}

Advanced age ( $\geq 60$ years) is a well-known independent risk factor for the development of PPCs after hip fracture surgery [21]. Earlier literature attributed the increased risk to the growing number of concomitant diseases with aging, rather than the effect of the chronological age itself [26]. For example, despite a 1.8-fold increase in mortality observed among patients older than 70 years of age compared with those 50-70 years old, the mortality was similar among patients in the same ASA class [27]. Recent studies have shown that advanced age is an independent predictor for PPCs, after controlling for the possible confounding factors in the multivariate analysis. When patients younger than 50 years old were used as the reference, the odds ratios (OR) for developing PPCs were 2.3, 3.9, and 5.6 for patients aged $60-69,70-79$, and $\geq 80$ years of age, respectively [21].

Since the incidence of hip fracture increases with age and surgery is the mainstay of treatment, advanced age alone is not a justified reason to preclude a patient from hip fracture surgery. Rather, patients should be evaluated for other modifiable risk factors and receive perioperative interventions to reduce the pulmonary complications after surgery.

Poor general health status

Poor general health status, including impaired sensorium and functional dependency, increases the risk of PPCs. Impaired sensorium is defined as either (1) an acutely confused or delirious patient who is able to respond to 
Table 2 Risk factors for the development of postoperative complications related to hip fracture surgery
ASA American Society of Anesthesiologist, BUN blood urea nitrogen

\begin{tabular}{ll}
\hline Patient-related risk factors & Procedure-related risk factors \\
\hline Advanced age ( $\geq 60$ years) & $\begin{array}{l}\text { Emergency surgery } \\
\text { Operation time } \geq 3 \mathrm{~h} \\
\text { Impaired sensorium }\end{array}$ \\
$\begin{array}{l}\text { Gunctional dependency anesthesia } \\
\text { Long-acting neuromuscular blockade use }\end{array}$ \\
ASA class $\geq 2$ & \\
Weight loss $>10 \%$ in previous 6 months & \\
Cigarette smoking & \\
Current respiratory infection or sepsis & \\
Congestive heart failure & \\
Chronic obstructive pulmonary disease & \\
Asthma & \\
Obstructive sleep apnea & \\
Ascites & \\
Albumin level $<35 \mathrm{~g} / \mathrm{L}$ & \\
Creatinine $\geq 1.5 \mathrm{mg} / \mathrm{dL}$ or BUN $\geq 21 \mathrm{mg} / \mathrm{dL}$ & \\
\hline
\end{tabular}

verbal stimulation, mild tactile stimulation, or both, or (2) a patient with mental status changes, delirium, or both in the context of current illness, modestly increase the risk of PPCs (OR 1.39) [21]. The OR of PPCs for total dependence and partial dependence were 2.51 and 1.65 , respectively [25].

The ASA physical status grading system, which was originally developed to describe patient's preoperative physical status, is a powerful predictor for PPCs among patients with COPD and asthma [28, 29]. It has long been shown that ASA class can predict the rate of PPCs among patients undergoing non-cardiothoracic surgery [30]. A recent systematic review considering multiple risk factors further confirmed that an ASA classification of 2 or higher has an increased risk of PPCs when compared with an ASA class of less than 2 (OR 4.87) [21].

\section{Cigarette smoking}

Cigarette smoking is a risk factor for PPCs, even in the absence of chronic lung disease or adjusting for other comorbidities commonly seen in smokers [31, 32]. Current smoker has an additional risk, and there is a correlation between the cumulative amount of smoking and the risk of PPCs [33]. A randomized, controlled trial has demonstrated that patients ceased smoking for 6-8 weeks before elective major orthopedic surgery had a reduced risk of PPCs [34]. However, the role of smoking cessation before hip fracture surgery remains controversial. Quitters may experience a 1to 2-week period of increased sputum production due to the improved respiratory mucociliary clearance [19]. Early studies even showed a paradoxical increase in PPCs among those patients who quit less than 6-8 weeks prior to surgery $[35,36]$, though this phenomenon has not been observed in a recent prospective study [37].
Despite the expected low impacts of smoking cessation before hip fracture surgery on preventing PPCs, an advice of quitting should be given to any smoker admitted to the hospital [38]. Physicians should advise patients to start a quit day after surgery and provide personalized counseling and pharmacotherapy, such as nicotine replacement therapy or varenicline, to those willing to quit [39-41].

\section{Current respiratory infection}

Current sputum production and pneumonia place the patient at risk for the development of PPCs. Therefore, antibiotics should be administered or hip fracture surgery should be delayed for as long as $72 \mathrm{~h}$ if bacterial infection is present in the lower respiratory tract. However, viral infection in the upper respiratory tract does not increase the risk of PPCs, even in asthmatic patients [29]. Prophylactic antibiotics covering Staphylococcus aureus, which are commonly given before hip fracture surgery to prevent wound infections, are also effective in reducing the risk of respiratory tract infection [42].

\section{Chronic respiratory symptoms}

The presence of chronic respiratory symptoms, such as chronic cough, dyspnea, or wheeze, is common among the elderly. In addition, diffuse rales, wheezing, or rhonchi may be identified on chest examination before surgery. Most of these symptoms and signs suggest the presence of underlying cardiopulmonary diseases, such as CHF, COPD, or uncontrolled asthma, which will then increase the risk of PPCs [43]. Physicians should take a detailed history and perform a focused cardiopulmonary examination, together with limited investigations to identify the causes of these unexplained chronic symptoms. 
A chest radiograph may reveal hyperinflation, cardiomegaly, or interstitial changes, which represent airway diseases, CHF, and interstitial lung diseases, respectively. Guidelines from the American College of Physicians suggest that spirometry should be performed in patients with unexplained respiratory symptoms before undergoing orthopedic surgery [44]. While spirometry with bronchodilator test is useful in demonstrating the presence, severity, and reversibility of airflow obstruction and, thus, differentiating asthma from COPD, lung volume measurements are also essential in confirming the presence of restrictive ventilatory defects, which is suggestive of interstitial lung disease, neuromuscular disease, or chest wall deformity [45]. Echocardiography may help to determine the systolic and diastolic heart function and the presence of pulmonary hypertension.

Chronic obstructive pulmonary disease

The presence of COPD increases the risk of PPCs by oneto twofold $[20,32,46]$. The increased risk in COPD patients attributes to the airflow obstruction and the presence of other co-morbidities commonly seen in smokers, such as CHF and weight loss. A correlation has been identified between the severity of the disease as defined by the percentage of $\mathrm{FEV}_{1}$ of predicted value and the risk of PPCs [47]. However, there is no prohibitive lower limit of $\mathrm{FEV}_{1}$ or FVC, which indicates that surgery should not be performed because operations could be safely carried out in patients with severe COPD [48].

Physicians should optimize the management of COPD before hip fracture surgery to minimize the risk of PPCs [49]. The commonly used preoperative management strategy can be remembered as A (antibiotic), B (bronchodilator), and $\mathrm{C}$ (corticosteroid) [50]. Antibiotics should be given for COPD patients with a recent change in the purulence or amount of sputum, as it is suggestive of an acute exacerbation caused by bacterial infection [51]. Anticholinergic agents and beta2-agonists are equally effective in reducing symptoms and airflow obstruction. The combination of these agents may provide further symptomatic relief [52]. Long-acting bronchodilators are more effective in reducing symptoms and airflow obstruction than their short-acting counterparts, partially due to their antiinflammatory effects [53, 54]. The use of systemic corticosteroid should be reserved for patients experiencing an acute exacerbation or those with persistent symptoms after maximal bronchodilators treatment [55].

Asthma

Well-controlled asthma is not a risk factor for PPCs. A study involving 706 asthmatic patients demonstrated that the rate of bronchospasm was just $1.7 \%$, while one respiratory failure and two additional laryngospasms occurred during the perioperative period. There were no other clinically significant PPCs or deaths in the entire group [29]. However, some clinical factors, including recent asthma symptoms, use of rescue inhalers, and medical consultation for asthmatic attack, were associated with an increased risk for PPCs [29].

Treatment with inhalers for asthma should be optimized prior to hip fracture surgery. Ideally, patients should be symptoms-free with a peak expiratory flow greater than $80 \%$ of the predicted or personal best value before surgery [56]. A short course of systemic corticosteroid (e.g., oral prednisone $0.5-1 \mathrm{mg} / \mathrm{kg}$ or equivalent), starting from 1 to 2 days before surgery, should be given to patients at risk for PPCs [57]. The perioperative use of systemic corticosteroid has not been found to increase respiratory infection or delay wound healing among asthmatic patients $[58,59]$.

\section{Obstructive sleep apnea}

OSA is a syndrome characterized by periodic, partial, or complete obstruction of the upper airway during sleep. A case-control study showed that there is a trend towards a higher rate of PPCs among patients with OSA undergoing major orthopedic surgery compared with those without [60]. The possible explanations of the increased risk of PPCs are: (1) OSA patients may have coexisting difficult airway and CHF, which may in turn increase the risk of PPCs [32], and (2) the use of anesthetics and analgesics that decrease pharyngeal tone and blunt the ventilatory response to hypoxia, together with supine positioning, may aggravate the severity of OSA during the perioperative period [61].

Patients should be screened for OSA before hip fracture surgery. Physicians should judge the probability of OSA based on the presence of risk factors and validated questionnaires. Major risk factors for OSA include male gender, obesity (body mass index $>35 \mathrm{~kg} / \mathrm{m}^{2}$ ), wide neck (neck circumference $>40 \mathrm{~cm}$ ), crowded oropharynx, and craniofacial abnormalities affecting the upper airway [62]. A four-question questionnaire known as "STOP" has been validated in screening perioperative patients for OSA [63]. Patients at risk for OSA should be asked the following four questions:

1. Snore: Do you snore loudly?

2. Tired: Do you often feel tired, fatigued, or sleepy during the day?

3. Observed: Has anyone observed you stop breathing during your sleep?

4. Blood pressure: Do you have or are you being treated for hypertension?

If a patient answers yes for two or more questions, he or she is at high risk for OSA. Continuous positive airway pressure 
(CPAP), the mainstay treatment for OSA, may be considered during the perioperative period, and elective polysomnography should be arranged later on [64]. For those with known OSA prior to hip fracture, adequate treatment, such as CPAP, mandibular advancement device, or oral appliances, should be provided as recommended by the guidelines from the American Society of Anaesthesiologists [62].

Other chronic lung diseases

Although other chronic lung diseases such as interstitial lung disease, neuromuscular disease, chest wall deformity, or pulmonary artery hypertension may increase the risk of PPCs after lung resection and other non-cardiothoracic surgery $[65,66]$, there is no strong evidence suggesting an increased risk for pulmonary complications after hip fracture surgery among patients with these conditions [25].

\section{Preoperative tests}

Preoperative tests such as chest radiograph, spirometry, or arterial blood gas should not be ordered as a routine before hip fracture surgery since the results of these tests have little impact on the perioperative management [25].

\section{Chest radiograph}

Routine chest radiograph should not be done for patients with hip fracture. A meta-analysis of studies involving 14,390 preoperative chest radiographs found that only 14 cases with chest radiographs were unexpectedly abnormal and management was changed [67]. Another study demonstrated that, despite a lower rate of PPCs in patients who received preoperative chest radiograph $(12.8 \%$ vs $16 \%)$, only $1-4 \%$ of the patients' managements were altered due to the result of chest radiograph [68]. Chest radiograph is only indicated in: (1) patients with unexplained respiratory symptoms or (2) suspected lower respiratory tract infection based on clinical findings.

Spirometry and arterial blood gas

Routine preoperative spirometry plays very little or no role in patients with hip fracture [25]. The predictive value of spirometry for PPCs is not better than those of clinical findings such as history and physical examination $[69,70]$. Guidelines recommend that preoperative spirometry is indicated in patients with unexplained respiratory symptoms before undergoing orthopedic surgery [44]. Spirometry is also helpful in determining whether patients with COPD or asthma are under optimal control before surgery. Early studies indicated that a partial pressure of arterial carbon dioxide $\left(\mathrm{PaCO}_{2}\right)$ greater than $45 \mathrm{mmHg}$ increases the risk of
PPCs [71, 72]. However, later studies have not shown the association between a raised $\mathrm{PaCO}_{2}$ and the PPCs risk [73].

\section{Risk-reduction interventions}

All patients at risk of PPCs should receive perioperative interventions in order to reduce PPCs. Apart from employing specific risk-reduction strategies to the abovementioned risk factors, physicians should implement general interventions, such as lung expansion maneuvers, thromboprophylaxis, and regional anesthesia/analgesia to reduce the risk of PPCs [74].

\section{Lung expansion techniques}

Lung expansion techniques, including deep-breathing exercises and incentive spirometry, are effective in reducing the risk of PPCs. Training on lung-expansion techniques should be provided to all patients at risk of PPCs. It has been shown that teaching patients these techniques preoperatively reduces pulmonary complications to a greater extent than instructions given after surgery [75]. Deep-breathing exercises and incentive spirometry are equally effective in reducing the risk of PPCs, and the latter is less laborintensive [76]. A review found that these techniques consistently reduced the relative risk of pulmonary complications by approximately $50 \%$ [77]. If patients at high-risk of PPCs are not able to perform these techniques, postoperative CPAP is a good alternative $[78,79]$.

Prophylaxis for venous thromboembolism

Patients with hip fracture are at high risk for the development of venous thromboembolism (VTE), including deep-vein thrombosis (DVT) and subsequent pulmonary embolism. Guidelines from the American College of Chest Physicians recommend that thromboprophylaxis should be administered among all patients undergoing hip fracture surgery for 10-35 days [80]. The drugs of choice include synthetic pentasaccharide (e.g., fondaparinux), lowmolecular-weight heparin (LMWH), low-dose unfractionated heparin (LDUH), and vitamin $\mathrm{K}$ antagonist (e.g., warfarin, targeting INR 2 to 3 ).

As concern for the timing of initiation, it is common to start thromboprophylaxis before surgery because DVT may begin during surgery [81]. However, recent evidence favors starting thromboprophylaxis after surgery due to the following reasons: (1) it provides comparable protection to the preoperative initiation of thromboprophylaxis [82], (2) it does not interfere with decisions about the use of regional anesthesia, and (3) it does not contribute to intraoperative bleeding. For hip fracture patients whose 
surgery is likely to be delayed, thromboprophylaxis with short-acting anticoagulant (e.g., LMWH or LDUH) should be initiated during the interval between hospital admission and surgery [80]. It should be noted that symptomatic breakthrough VTE, primarily distal DVT, may develop in $9 \%$ of patients undergoing hip fracture surgery despite standard thromboprophylaxis [83].

Recent studies have shown that dabigatran etexilate, an oral direct thrombin inhibitor not requiring frequent laboratory monitoring as warfarin, is at least as effective as LMWH for the prevention of VTE following major orthopedic surgery [84, 85]. For patients with high risk of bleeding or contraindications to any form of anticoagulation, mechanical prophylactic measures, such as pneumatic sequential leg compression or graduated compression stockings should be given [86].

\section{Regional anesthesia and analgesia}

A meta-analysis involving 141 randomized controlled trials reported that patients receiving regional anesthesia (either spinal or epidural anesthesia) had lower rates of pneumonia and respiratory failure as compared with those under general anesthesia [87]. However, another systematic review involving 15 randomized trials of 2,162 patients focusing on hip fracture surgery found that the postoperative pneumonia rates were almost the same $(5.1 \%$ in regional vs $5.5 \%$ in general anesthesia) [88].

Postoperative epidural analgesia is associated with the lowest rate of PPCs compared with other forms of analgesia among patients after major abdominal surgery [21]. However, to date, there seems to have been no study investigating the difference in PPCs among those patients undergoing hip fracture surgery. Further investigations are needed to demonstrate the beneficial effects of regional anesthetics and analgesics on PPCs among patients receiving hip fracture surgery. It is conceivable that spinal/ epidural hematoma may occur in anticoagulated patients who are receiving regional anesthesia or analgesia. However, a recent study found that well-controlled anticoagulation was not associated with an increased risk of postoperative spinal/epidural hematoma [89].

\section{Conclusion}

Hip fracture is a common cause of morbidity and mortality among the elderly. PPCs play an important role in altering the risk for patients undergoing hip fracture surgery. Physicians should perform preoperative pulmonary assessment, taking into account the patient-related risk factors such as advanced age, poor general health status, current infections, underlying cardiopulmonary diseases, hypoalbuminemia, and impaired renal function. At the same time, efforts should be made to optimize the patient's medical conditions prior to surgery, and preoperative interventions such as lung expansion techniques and thromboprophylaxis should be employed in order to minimize the pulmonary risk.

\section{Conflicts of interest None.}

Open Access This article is distributed under the terms of the Creative Commons Attribution Noncommercial License which permits any noncommercial use, distribution, and reproduction in any medium, provided the original author(s) and source are credited.

\section{References}

1. Dharmarajan TS, Banik P (2006) Hip fracture. Risk factors, preoperative assessment, and postoperative management. Postgrad Med 119:31-38

2. Cooper C, Campion G, Melton LJ (1992) Hip fractures in the elderly: a world-wide projection. Osteoporos Int 2:285-289

3. Raaymakers EL (2006) Fractures of the femoral neck: a review and personal statement. Acta Chir Orthop Traumatol Cech 73:45-59

4. Lu-Yao GL, Baron JA, Barrett JA, Fischer ES (1994) Treatment and survival among elderly Americans with hip fractures: a population-based study. Am J Public Health 84:1287-1291

5. Goldacre MJ, Roberts SE, Yeates D (2002) Mortality after admission to hospital with fractured neck of femur: database study. BMJ 325:868-869

6. Magaziner J, Simonsick EM, Kashner TM, Hebel JR, Kenzora JE (1990) Predictors of functional recovery one year following hospital discharge for hip fracture: a prospective study. J Gerontol 45:M101-M107

7. Orosz GM, Magaziner J, Hannan EL et al (2004) Association of timing of surgery for hip fracture and patient outcomes. JAMA 291:1738-1743

8. Bottle A, Aylin P (2006) Mortality associated with delay in operation after hip fracture: observational study. BMJ 332:947-951

9. Shiga T, Wajima Z, Ohe Y (2008) Is operative delay associated with increased mortality of hip fracture patients? Systematic review, metaanalysis, and meta-regression. Can J Anaesth 55:146-154

10. Lawrence VA, Hilsenbeck SG, Mulrow CD, Dhanda R, Sapp J, Page CP (1995) Incidence and hospital stay for cardiac and pulmonary complications after abdominal surgery. J Gen Intern Med 10:671-678

11. French DD, Bass E, Bradham DD, Campbell RR, Rubenstein LZ (2008) Rehospitalization after hip fracture: predictors and prognosis from a national veterans study. J Am Geriatr Soc 56:705-710

12. Yonezawa T, Yamazaki K, Atsumi T, Obara S (2009) Influence of the timing of surgery on mortality and activity of hip fracture in elderly patients. J Orthop Sci 14:566-573

13. Smetana GW (1999) Preoperative pulmonary evaluation. N Engl J Med 340:937-944

14. Liu LL, Leung JM (2000) Predicting adverse postoperative outcomes in patients aged 80 years or older. J Am Geriatr Soc 48:405-412

15. Lawrence VA, Hilsenbeck SG, Noveck H, Poses RM, Carson JL (2002) Medical complications and outcomes after hip fracture repair. Arch Intern Med 162:2053-2057 
16. Manku K, Bacchetti P, Leung JM (2003) Prognostic significance of postoperative inhospital complications in elderly patients. I. Long-term survival. Anesth Analg 96:583-589

17. Khuri SF, Henderson WG, DePalma RG, Mosca C, Healey NA, Kumbhani DJ (2005) Determinants of long-term survival after major surgery and the adverse effect of postoperative complications. Ann Surg 242:326-341

18. Swenson ER (2004) Preoperative pulmonary evaluation. In: Albert RK, Spiro S, Jett J (eds) Clinical respiratory medicine, 2nd edn. Elsevier Science, Philadelphia, pp 229-234

19. Smetana GW (2003) Preoperative pulmonary assessment of the older adult. Clin Geriatr Med 19:35-55

20. Fisher BW, Majumdar SR, McAlister FA (2002) Predicting pulmonary complications after nonthoracic surgery: a systematic review of blinded studies. Am J Med 112:219-225

21. Smetana GW, Lawrence VA, Cornell JE (2006) Preoperative pulmonary risk stratification for noncardiothoracic surgery: systematic review for the American College of Physicians. Ann Intern Med 144:581-595

22. Arozullah AM, Daley J, Henderson WG, Khuri SF (2000) Multifactorial risk index for predicting postoperative respiratory failure in men after major noncardiac surgery: the National Veterans Administration Surgical Quality Improvement Program. Ann Surg 232:242-253

23. Arozullah AM, Khuri SF, Henderson WG, Daley J (2001) Development and validation of a multifactorial risk index for predicting postoperative pneumonia after major noncardiac surgery. Ann Intern Med 135:847-857

24. Johnson RG, Arozullah AM, Neumayer L, Henderson WG, Hosokawa P, Khuri SF (2007) Multivariable predictors of postoperative respiratory failure after general and vascular surgery: results from the patient safety in surgery study. J Am Coll Surg 204:1188-1198

25. Qaseem A, Snow V, Fitterman N et al (2006) Risk assessment for and strategies to reduce perioperative pulmonary complications for patients undergoing noncardiothoracic surgery: a guideline from the American College of Physicians. Ann Intern Med 144:575-580

26. Polanczyk CA, Marcantonio E, Goldman L, Rohde LE, Orav J, Mangione CM, Lee TH (2001) Impact of age on perioperative complications and length of stay in patients undergoing noncardiac surgery. Ann Intern Med 134:637-643

27. Marx GF, Mateo CV, Orkin LR (1973) Computer analysis of postanesthetic deaths. Anesthesiology 39:54-58

28. Wong D, Weber EC, Schell MJ, Wong AB, Anderson CT, Barker SJ (1995) Factors associated with postoperative pulmonary complications in patients with severe chronic obstructive pulmonary disease. Anesth Analg 80:276-284

29. Warner DO, Warner MA, Barnes RD, Offord KP, Schroeder DR, Gray DT, Yunginger JW (1996) Perioperative respiratory complications in patients with asthma. Anesthesiology 85:460-467

30. Owens WD, Felts JA, Spitznagel EL Jr (1978) ASA physical status classifications: a study of consistency of ratings. Anesthesiology 49:239-243

31. Warner DO (2006) Perioperative abstinence from cigarettes. Anesthesiology 104:356-67

32. McAlister FA, Khan NA, Straus SE, Papaioakim M, Fisher BW, Majumdar SR, Gajic O, Daniel M, Tomlinson G (2003) Accuracy of the preoperative assessment in predicting pulmonary risk after nonthoracic surgery. Am J Respir Crit Care Med 167:741-744

33. Warner MA, Divertie MB, Tinker JH (1984) Preoperative cessation of smoking and pulmonary complications in coronary artery bypass patients. Anesthesiology 60:380-383

34. Møller AM, Villebro N, Pedersen T, Tønnesen H (2002) Effect of preoperative smoking intervention on postoperative complications: a randomized clinical trial. Lancet 359:114-117
35. Warner MA, Offord KP, Warner ME, Lennon RL, Conover MA, Jansson-Schumacher U (1989) Role of preoperative cessation of smoking and other factors in postoperative pulmonary complications: a blinded prospective study of coronary artery bypass patients. Mayo Clin Proc 64:609-616

36. Bluman LG, Mosca L, Newman N, Simon DG (1998) Preoperative smoking habits and postoperative pulmonary complications. Chest 113:883-889

37. Barrera R, Shi W, Amar D, Thaler HT, Gabovich N, Bains MS, White DA (2005) Smoking and timing of cessation: impact on pulmonary complications after thoracotomy. Chest 127:19771983

38. Clinical Practice Guideline Treating Tobacco Use and Dependence 2008 Update Panel, Liaisons, and Staff (2008) A clinical practice guideline for treating tobacco use and dependence: 2008 update. A U.S. Public Health Service report. Am J Prev Med $35: 158-176$

39. Niaura R (2008) Non-pharmacologic therapy for smoking cessation: characteristics and efficacy of current approaches. Am J Med 131:S11-S19

40. Stead LF, Perera R, Bullen C et al (2008) Nicotine replacement therapy for smoking cessation. Cochrane Database Syst Rev 1: CD000146

41. Hays JT, Ebbert JO (2008) Varenicline for tobacco dependence. N Engl J Med 359:2018-2014

42. Gillespie WJ, Walenkamp GH (2010) Antibiotic prophylaxis for surgery for proximal femoral and other closed long bone fractures. Cochrane Database Syst Rev 3:CD000244

43. Epstein SK, Faling LJ, Daly BD, Celli BR (1993) Predicting complications after pulmonary resection: preoperative exercise testing vs a multifactorial cardiopulmonary risk index. Chest 104:694-700

44. American College of Physicians (1990) Preoperative pulmonary function testing. Ann Intern Med 112:793-794

45. Pellegrino R, Viegi G, Brusasco V et al (2005) Interpretative strategies for lung function tests. Eur Respir J 26:948-968

46. Warner DO, Warner MA, Offord KP, Schroeder DR, Maxson P, Scanlon PD (1999) Airway obstruction and perioperative complications in smokers undergoing abdominal surgery. Anesthesiology 90:372-379

47. Gass GD, Olsen GN (1986) Preoperative pulmonary function testing to predict postoperative morbidity and mortality. Chest 89:127-135

48. Kroenke K, Lawrence VA, Theroux JF, Tuley MR (1992) Operative risk in patients with severe obstructive pulmonary disease. Arch Intern Med 152:967-971

49. Alifano M, Cuvelier A, Roche DN, Lamia B, Molano LC, Couderc LJ, Marquette CH, Devillier P (2010) Treatment of COPD: from pharmacological to instrumental therapies. Eur Respir Rev 19:7-23

50. Rabe KF, Hurd S, Anzueto A et al (2007) Global strategy for the diagnosis, management, and prevention of chronic obstructive pulmonary disease: GOLD executive summary. Am J Respir Crit Care Med 176:532-555

51. Wilson R, Jones P, Schaberg T, Arvis P, Duprat-Lomon I, Sagnier PP (2006) Antibiotic treatment and factors influencing short and long term outcomes of acute exacerbations of chronic bronchitis. Thorax 61:337-342

52. McCrory DC, Brown CD (2002) Anti-cholinergic bronchodilators versus beta2-sympathomimetic agents for acute exacerbations of chronic obstructive pulmonary disease. Cochrane Database Syst Rev 4:CD003900

53. Johnson M, Rennard S (2001) Alternative mechanisms for longacting beta2-adrenergic agonists in COPD. Chest 120:258-270

54. Buhling F, Lieder N, Reisenauer A, Welte T (2004) Antiinflammatory effect of tiotropium mediated by suppression of 
acetylcholine-induced release of chemotactic activity. Eur Respir J 24:318S

55. Davies L, Angus RM, Calverley PM (1999) Oral corticosteroids in patients admitted to hospital with exacerbations of chronic obstructive pulmonary disease: a prospective randomised controlled trial. Lancet 354:456-460

56. Bateman ED, Hurd SS, Barnes PJ et al (2008) Global strategy for asthma management and prevention: GINA executive summary. Eur Respir J 31:143-178

57. Silvanus MT, Groeben H, Peters J (2004) Corticosteroids and inhaled salbutamol in patients with reversible airway obstruction markedly decrease the incidence of bronchospasm after tracheal intubation. Anesthesiology 100:1052-1057

58. Pien LC, Grammer LC, Patterson R (1988) Minimal complications in a surgical population with severe asthma receiving prophylactic corticosteroids. J Allergy Clin Immunol 82:696-700

59. Kabalin CS, Yarnold PR, Grammer LC (1995) Low complication rate of corticosteroid-treated asthmatics undergoing surgical procedures. Arch Intern Med 155:1379-1384

60. Grupta R, Parvizi J, Hanssen A, Gay P (2001) Postoperative complications in patients with obstructive sleep apnea syndrome undergoing hip or knee replacement: a case-control study. Mayo Clin Proc 76:897-905

61. Rock P, Passannante A (2004) Preoperative assessment: pulmonary. Anesthesiol Clin N Am 22:77-91

62. American Society of Anesthesiologists Task Force on Perioperative Management of Patients with Obstructive Sleep Apnea (2006) Practice guidelines for the perioperative management of patients with obstructive sleep apnea. Anesthesiology 104:10811093

63. Chung F, Yegneswaran B, Liao P, Chung SA, Vairavanathan S, Islam S, Khajehdehi A, Shapiro CM (2008) STOP questionnaire: a tool to screen patients for obstructive sleep apnea. Anesthesiology 108:812-821

64. Ulnick K, Debo R (2000) Postoperative management of the patient with obstructive sleep apnea. Otolaryngol Head Neck Surg 122:233-236

65. Martinod E, Azorin JF, Sadoun D, Destable MD, Le Toumelin P, Longchampt E, Kambouchner M, Guillevin L, Valeyre D (2002) Surgical resection of lung cancer in patients with underlying interstitial lung disease. Ann Thorac Surg 74:1004-1007

66. Ramakrishna G, Sprung J, Ravi BS, Chandrasekaran K, McGoon MD (2005) Impact of pulmonary hypertension on the outcomes of noncardiac surgery: predictors of perioperative morbidity and mortality. J Am Coll Cardiol 45:1691-1699

67. Archer C, Levy AR, McGregor M (2003) Value of routine preoperative chest $\mathrm{x}$-rays: a meta-analysis. Can $\mathrm{J}$ Anaesth 40:1022-1027

68. Joo HS, Wong J, Naik VN, Savoldelli GL (2005) The value of screening preoperative chest $\mathrm{x}$-rays: a systematic review. Can J Anaesth 52:568-574

69. Williams-Russo P, Charlson ME, MacKenzie CR, Gold JP, Shires GT (1992) Predicting postoperative pulmonary complications: is it a real problem? Arch Intern Med 152:1209-1213

70. Lawrence VA, Dhanda R, Hilsenbeck SG, Page CP (1996) Risk of pulmonary complications after elective abdominal surgery. Chest 110:744-750

71. Milledge JS, Nunn JF (1975) Criteria of fitness for anaesthesia in patients with chronic obstructive lung disease. BMJ 3:670-673

72. Stein M, Koota GM, Simon M, Frank HA (1962) Pulmonary evaluation of surgical patients. JAMA 181:765-770
73. Kearney DJ, Lee TH, Reilly JJ, DeCamp MM, Sugarbaker DJ (1994) Assessment of operative risk in patients undergoing lung resection: importance of predicted pulmonary function. Chest 105:753-759

74. Lawrence VA, Cornell JE, Smetana GW (2005) Strategies to reduce postoperative pulmonary complications after noncardiothoracic surgery: systematic review for the American College of Physicians. Ann Intern Med 144:596-608

75. Castillo R, Haas A (1985) Chest physical therapy: comparative efficacy of preoperative and postoperative in the elderly. Arch Phys Med Rehabil 66:376-379

76. Thomas JA, McIntosh JM (1994) Are incentive spirometry, intermittent positive pressure breathing, and deep breathing exercises effective in the prevention of postoperative pulmonary complications after upper abdominal surgery? A systematic overview and meta-analysis. Phys Ther 74:3-16

77. Brooks-Brunn JA (1995) Postoperative atelectasis and pneumonia. Heart Lung 24:94-115

78. Stock MC, Downs JB, Gauer PK, Alster JM, Imrey PB (1985) Prevention of postoperative pulmonary complications with CPAP, incentive spirometry, and conservative therapy. Chest 87:151-157

79. Squadrone V, Coha M, Cerutti E et al (2005) Continuous positive airway pressure for treatment of postoperative hypoxemia: a randomized controlled trial. JAMA 293:589-595

80. Geerts WH, Bergqvist D, Pineo GF, Heit JA, Samama CM, Lassen MR, Colwell CW (2008) Prevention of venous thromboembolism: American College of Chest Physicians Evidence-Based Clinical Practice Guidelines (8th Edition). Chest 133:381S-453S

81. Morrison RS, Chassin MR, Siu AL (1998) The medical consultant's role in caring for patients with hip fracture. Ann Intern Med 128:1010-1020

82. Hull RD, Pineo GF, Francis C et al (2000) Low-molecular-weight heparin prophylaxis using dalteparin in close proximity to surgery vs warfarin in hip arthroplasty patients: a doubleblind, randomized comparison. Arch Intern Med 160:2199-2207

83. Schiff RL, Kahn SR, Shrier I, Strulovitch C, Hammouda W, Cohen E, Zukor D (2005) Identifying orthopedic patients at high risk for venous thromboembolism despite thromboprophylaxis. Chest 128:3364-3371

84. Eriksson BI, Dahl OE, Rosencher N et al (2007) Dabigatran etexilate versus enoxaparin for prevention of venous thromboembolism after total hip replacement: a randomised, double-blind, non-inferiority trial. Lancet 370:949-956

85. Eriksson BI, Dahl OE, Rosencher N et al (2007) Oral dabigatran etexilate vs. subcutaneous enoxaparin for the prevention of venous thromboembolism after total knee replacement: the RE-MODEL randomized trial. J Thromb Haemost 5:2178-2185

86. Handoll HH, Farrar MJ, McBirnie J, Tytherleigh-Strong G, Milne AA, Gillespie WJ (2002) Heparin, low molecular weight heparin and physical methods for preventing deep vein thrombosis and pulmonary embolism following surgery for hip fractures. Cochrane Database Syst Rev 4:CD000305

87. Rodgers A, Walker N, Schug S et al (2000) Reduction of postoperative mortality and morbidity with epidural or spinal anaesthesia: results from overview of randomised trials. BMJ 321:1493

88. Urwin SC, Parker MJ, Griffiths R (2000) General versus regional anaesthesia for hip fracture surgery: a meta-analysis of randomized trials. Br J Anaesth 84:450-455

89. Awad JN, Kebaish KM, Donigan J, Cohen DB, Kostuik JP (2005) Analysis of the risk factors for the development of post-operative spinal epidural hematoma. J Bone Joint Surg Br 87:1248-1252 